\title{
Synthesis of 3,3-Arylidene Bis(4-Hydroxycoumarin) Catalyzed by $p$-Dodecylbenzenesulfonic Acid (DBSA) in Aqueous Media and Microwave Irradiation
}

\author{
Asiyeh Shamsaddini, Enayatollah Sheikhhosseini* \\ Department of Chemistry, Faculty of Science, Kerman Branch, Islamic Azad University, Kerman, Iran \\ Email: ${ }^{*}$ sheikhhosseiny@gmail.com
}

Received 13 April 2014; revised 16 May 2014; accepted 24 May 2014

Copyright (C) 2014 by authors and Scientific Research Publishing Inc. This work is licensed under the Creative Commons Attribution International License (CC BY). http://creativecommons.org/licenses/by/4.0/

(c) (i) Open Access

\section{Abstract}

A series of 3,3-arylidene bis(4-hydroxycoumarins) were synthesized by the reaction of aromatic aldehydes with 4-hydroxycoumarin using dodecylbenzenesulfonic acid as Brønsted acid-surfactant catalyst in aqueous media and under microwave irradiation. The present method is operationally simple and the use of water as the reaction medium makes the process environmentally benign.

\section{Keywords}

3,3-Arylidene Bis(4-Hydroxycoumarin), 4-Hydroxycoumarin, Microwave Irradiation, $p$-Dodecylbenzenesulfonic Acid (DBSA), Aqueous Media

\section{Introduction}

Many of coumarin derivatives are biologically active [1] [2]. A great volume of studies have attempted to inhibit bacterial growth using naturally occurring coumarins, such as herniarin, umbelliferone and scopoletin on the antifungal activity of umbelliferone, scopoletin and coumarin itself [3] [4]. Some coumarin derivatives, including novobiocin and analogues, have been demonstrated to be very active as antibiotics [5]-[7]. Among synthetic derivatives, several antibacterial 3-acyl and 3-carba-moyl-4-hydroxycoumarins [8]-[12] have been described.

Bis-coumarins are generally prepared by condensing carbonyl compounds with 4-hydroxycoumarin in organic solvents [13] [14], which applied a large number of hazardous and toxic solvents related to catalysts. Several

\footnotetext{
${ }^{*}$ Corresponding author.
} 
methods have been recently reported for such synthesis which includes use of different catalysts such as molecular iodine [15], $\mathrm{MnCl}_{2}$ [16], strong tertiary amine base (DBU) [17], $\mathrm{POCl}_{3}$ [18], diethyl aluminum chloride $\left(\mathrm{Et}_{2} \mathrm{AlCl}_{3}\right)$ [19], $\mathrm{LiClO}_{4}$ [20], $\mathrm{SO}_{3} \mathrm{H}$ functionalized, ionic liquids [21], SDS [22], TBAB [23], Zn(Proline $)_{2}$ [24], [bmim] [BF4] [25], sulfamic acid [26], $\mathrm{RuCl}_{3} \cdot \mathrm{nH}_{2} \mathrm{O}$ [27], $\mathrm{SiO}_{2} \mathrm{Cl}$ [28], $\mathrm{SiO}_{2}-\mathrm{OSO}_{3} \mathrm{H}$ NPs [29], Sulfated titania [30] refluxing in ethanol or acetic acid [31], thermal solvent-free microwave, ultrasound condition [32] [33] etc.

With the growing public concern about the environment, several synthesis methods using 4-hydroxycoumarin have been recently proposed for preparing biscoumarins in aqueous media. Despite the efficacy and eco-friendliness of these methods, they use catalysts including TEBA [34] and $\mathrm{I}_{2}$ [35] and have long reaction times. Thus, it is still required to propose efficient and novel methods based on green methodology.

p-Dodecylbenzenesulfonic acid (DBSA) is a Brønsted acidsurfactant-combined catalyst, which is composed of an acidic group and a hydrophobic moiety. It could be explained that the inside of emulsion droplets composed of substrate and DBSA is hydropho-bic enough to exclude water molecules. Therefore, surfactant-catalyzed organic reactions in water have turned to be one of the most challenging research issues. The behavior of DBSA as a catalyst has been studied in Mannich type reactions, Biginelli reaction, synthesis of bis (indol-3-yl) alkanes, tetrahydrobenzo $[b]$ pyrans, dihydropyrano $[c]$ chromens, xanthenes derivatives and esterification of various carboxylic acids and alcohols [36]-[42]. In the present work, these results were reported for the synthesis of 3,3-Arylidene bis(4-hydroxycoumarin) derivatives by DBSA in environmentally benign conditions and under microwave irradiation.

\section{Result and Discussion}

In this paper, efficient method was tried to be proposed for the condensation of aldehydes with 4-hydroxycoumarin, which led to the corresponding 3,3-arylidene bis(4hydroxycoumarin) in the presence of DBSA as a homogeneous catalyst in two methods (A, B) (Scheme 1). DBSA was used as a source of $\mathrm{H}^{+}$to catalyze this reaction and found to be a good catalyst for the preparation of 3,3-arylidene bis(4-hydroxycoumarin).

Initially, the systematic evaluation of different solvents for the model reaction of 3-nitro benzaldehyde and 4-hydroxycoumarin in the presence of DBSA in water at reflux was focused on. Attempts were made to study and optimize the reaction conditions in order to show that performing the reaction $\mathrm{in}_{2} \mathrm{O}$ with low yield while using the amounts of EtOH in the media produced satisfactory results (Table 1, entry 6). These results revealed that the highest yield was obtained with the water/ethanol (1:1) solvent system (Table 1, entry 6).

Since DBSA was emerged as a suitable catalyst for the reaction in 1:1 ethanol/water media, then efforts were made to optimize the catalyst load for the condensation reaction, leading to the rapid formation of 3,3-arylidene bis(4-hydroxycoumarin). The present optimization studies revealed that the yield smoothly increased with the catalyst load up to $25 \mathrm{~mol} \%$ and the use of larger amounts of the catalyst did not improve the yields, while its decreasing amount decreased the yields. The negligible amount of the product was formed in the absence of catalyst.

To find the specific effect of microwave irradiation on the reaction, these reactions were carried out under the same conditions in a microwave oven (Table 1, entry 13) and it was observed that, while the reaction time considerably decreased, the yields of the product slightly increased. Thus, MW conditions had a beneficial effect on this reaction. Afterward, concentration was within the scope of this reaction with the variety of aldehydes (Scheme 1) in order to check the viability of this protocol in obtaining a library of 3,3-arylidene bis(4-hydroxycoumarin) derivatives in two methods (Table 2).

As can be seen in Table 2, a range of dicoumarols was synthesized using different aldehydes and 4-hydroxycoumarin under the standardized reaction. The results are summarized in Table 2. Regardless of the nature of the substitution (electron donating and electron withdrawing) of the aromatic aldehydes, the products were obtained in good to excellent yields (entries 1 - 17). Similar results were also obtained in the microwave condition

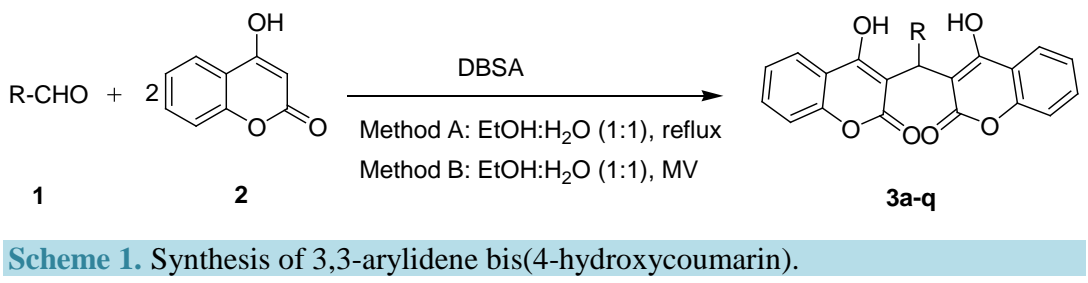


Table 1. Optimization of reaction condition on the yield of 3,3-arylidene bis(4-hydroxycoumarin).

\begin{tabular}{cccccc}
\hline Entry & Catalyst & Solvent & Temperature & Time (min) & Yield (\%) \\
\hline 1 & without DBSA & $\mathrm{H}_{2} \mathrm{O}$ & reflux & 240 & trace \\
2 & DBSA (25\%) & $\mathrm{H}_{2} \mathrm{O}$ & reflux & 75 & 85 \\
3 & DBSA (25\%) & $\mathrm{EtOH}$ & r.t. & 120 & trace \\
4 & DBSA (25\%) & $\mathrm{EtOH}$ & reflux & 60 & 87 \\
5 & DBSA (25\%) & $\mathrm{MeOH}$ & reflux & 405 & 80 \\
6 & DBSA (25\%) & EtOH: $\mathrm{H}_{2} \mathrm{O}(1: 1)$ & reflux & 94 \\
7 & DBSA (25\%) & MeOH: $\mathrm{H}_{2} \mathrm{O}(1: 1)$ & reflux & 65 & 90 \\
8 & DBSA (25\%) & EtOH: $\mathrm{H}_{2} \mathrm{O}(1: 1)$ & r.t. & 40 & trace \\
9 & DBSA (10\%) & EtOH: $\mathrm{H}_{2} \mathrm{O}(1: 1)$ & reflux & 40 & 68 \\
10 & DBSA (15\%) & EtOH: $\mathrm{H}_{2} \mathrm{O}(1: 1)$ & reflux & 40 & 70 \\
11 & DBSA (20\%) & EtOH: $\mathrm{H}_{2} \mathrm{O}(1: 1)$ & reflux & 40 & 72 \\
13 & DBSA (30\%) & EtOH: $\mathrm{H}_{2} \mathrm{O}(1: 1)$ & reflux & 40 & 93 \\
\hline
\end{tabular}

${ }^{\mathrm{a}}$ Isolated yield.

Table 2. Synthesis of 3,3-arylidene bis(4-hydroxycoumarin) by condensation of aldehydes and 4-hydroxycoumarin using DBSA (25 mol\%) as catalyst.

\begin{tabular}{|c|c|c|c|c|c|c|}
\hline Entry & $\mathrm{R}$ & Product & $\begin{array}{l}\text { Method A Time } \\
\text { (min)/yield (\%) }\end{array}$ & $\begin{array}{l}\text { Method A Time } \\
\text { (min)/yield (\%) }\end{array}$ & \multicolumn{2}{|c|}{ M.P. $\left({ }^{\circ} \mathrm{C}\right)$ Found reported } \\
\hline 1 & $\mathrm{C}_{6} \mathrm{H}_{5-}^{-}$ & $3 a$ & $60 / 80$ & $6.5 / 84$ & $232-234$ & $230-232[22]$ \\
\hline 2 & $3-\mathrm{NO}_{2} \mathrm{C}_{6} \mathrm{H}_{4-}$ & $3 b$ & $45 / 90$ & $7.5 / 80$ & $234-236$ & $234-236[22]$ \\
\hline 3 & $4-\mathrm{NO}_{2} \mathrm{C}_{6} \mathrm{H}_{4-}^{-}$ & 3c & $60 / 90$ & $4.5 / 90$ & $237-240$ & $232-234[22]$ \\
\hline 4 & $3-\mathrm{BrC}_{6} \mathrm{H}_{4}-$ & $3 d$ & $60 / 87$ & $7.0 / 92$ & $225-228$ & $287[12]$ \\
\hline 5 & $4-\mathrm{ClC}_{6} \mathrm{H}_{4}-$ & 3e & $60 / 85$ & $5.5 / 76$ & $258-260$ & $256-258[22]$ \\
\hline 6 & $2,4-(\mathrm{Cl})_{2} \mathrm{C}_{6} \mathrm{H}_{3-}$ & $3 f$ & $90 / 88$ & 8.0/85 & $190-195$ & 198 - 200 [29] \\
\hline 7 & $2,6-(\mathrm{Cl})_{2} \mathrm{C}_{6} \mathrm{H}_{3-}$ & $3 g$ & $45 / 90$ & $6.0 / 93$ & $125-130$ & $178-180[28]$ \\
\hline 8 & $2-\mathrm{MeC}_{6} \mathrm{H}_{4}-$ & 3h & $90 / 85$ & $8.5 / 83$ & $218-220$ & $221-223[22]$ \\
\hline 9 & $4-\mathrm{MeC}_{6} \mathrm{H}_{4}-$ & $3 \mathrm{i}$ & $78 / 85$ & $6.5 / 85$ & $266-265$ & 266 - 268 [22] \\
\hline 10 & $2-\mathrm{MeOC}_{6} \mathrm{H}_{4-}$ & $3 \mathrm{j}$ & $90 / 80$ & $8.0 / 82$ & $213-215$ & $214-215$ [13] \\
\hline 11 & 4- $\mathrm{MeOC}_{6} \mathrm{H}_{4-}^{-}$ & $3 \mathrm{k}$ & $90 / 87$ & $8.0 / 90$ & $249-251$ & $246-248[22]$ \\
\hline 12 & $2,4-(\mathrm{MeO})_{2} \mathrm{C}_{6} \mathrm{H}_{3}-$ & 31 & $120 / 75$ & $10.0 / 75$ & $203-205$ & 197 - 198 [13] \\
\hline 13 & $3,4,5-(\mathrm{MeO})_{3} \mathrm{C}_{6} \mathrm{H}_{2-}$ & $3 \mathrm{~m}$ & $120 / 70$ & $9.0 / 68$ & $240-245$ & $241-243[13]$ \\
\hline 14 & $2-\mathrm{HOC}_{6} \mathrm{H}_{4}^{-}$ & $3 n$ & $90 / 86$ & 8.5/88 & $250-255$ & $254-256[15]$ \\
\hline 15 & 4- $\left(\mathrm{Me}_{2} \mathrm{~N}\right) \mathrm{C}_{6} \mathrm{H}_{4^{-}}$ & 3о & $90 / 80$ & $8.5 / 87$ & $210-215$ & $216-217$ [26] \\
\hline 16 & Propionaldehyde & 3p & $60 / 87$ & $6.0 / 92$ & $140-142$ & 144 - $146[27]$ \\
\hline 17 & 2-(Prop-2-ynyloxy)- $\mathrm{C}_{10} \mathrm{H}_{6^{-}}$ & $3 q$ & $150 / 60$ & $15 / 78$ & $168-172$ & - \\
\hline
\end{tabular}

Method A: EtOH: $\mathrm{H}_{2} \mathrm{O}$ (1:1), reflux; Method B: EtOH: $\mathrm{H}_{2} \mathrm{O}$ (1:1), MV. 
(Method B). All the reactions were completed within 45 - 150 min and 4.5 - 15 min in Methods A and B, respectively. In these reactions, there was no need for the column purification of the products. The obtained solid products were just filtered off from the reaction mixture, dissolved in hot ethanol, refiltered to separate any contaminated catalyst with the product and finally recrystallized from the filtrate to obtain pure dicoumarols.

According to the proposed mechanism, the formation of 3,3-arylidene bis(4-hydroxycoumarin) could be rationalized from the Knoevenagel condensation of aromatic aldehydes with 4-hydroxycoumarin in the presence of DBSA and followed by Michele addition of the second 4-hydroxycoumarin (Scheme 2).

To show the advantage of the present work in comparison with the reported results in the literature, the results of DBSA with reflux in ethanol or acetic acid, iodine, DBU, SDS, TBAB, $\mathrm{TiO}_{2} / \mathrm{SO}_{4}^{-2}$ and $\mathrm{SiO}_{2} / \mathrm{Cl}$ were compared in terms of the synthesis of biscoumarin derivatives. As shown in Table 3, DBSA can act as an effective catalyst with respect to reaction time, yields and the obtained products.

In conclusion, DBSA was demonstrated a new efficient catalyst for the synthesis of dicoumarols, prepared via the condensation reaction of aromatic aldehyde and 4-hydroxycoumarin using DBSA as a homogeneous catalyst under aqueous media and microwave conditions. These conditions had advantages such as shorter reaction time, simpler work-up, inexpensive and non-toxic catalysis, environmental benignity and excellent yields.

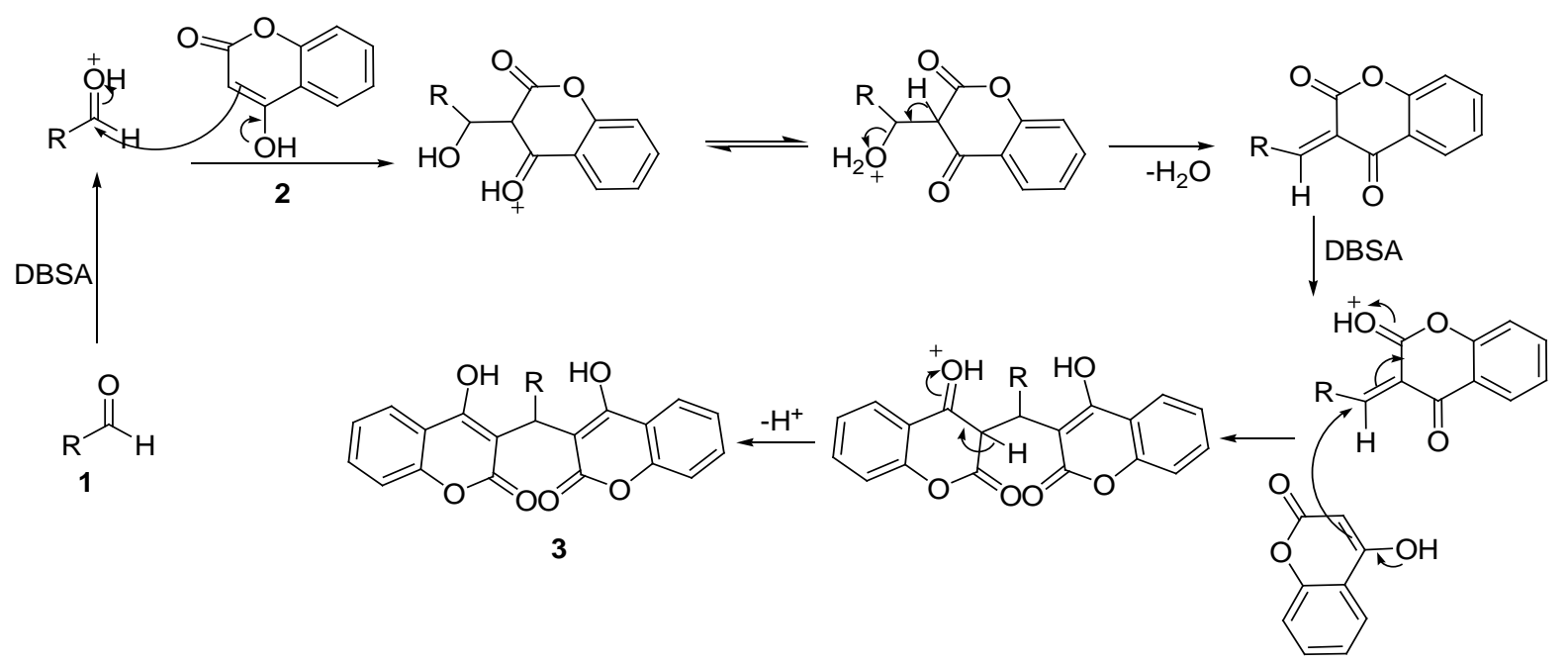

Scheme 2. Proposed mechanism.

Table 3. Comparison of our results with some of those reported in the literature for the reaction of 4-nitro benzaldehyde, malononitrile and 4-hydroxycoumarin.

\begin{tabular}{|c|c|c|c|c|}
\hline Entry & Reaction condition & Yield (\%) & Time & Ref. \\
\hline 1 & Reflux ethanol or acetic acid & 71 & $5-6 \mathrm{~h}$ & [30] \\
\hline 2 & $\mathrm{I}_{2}(10 \mathrm{~mol} \%), \mathrm{H}_{2} \mathrm{O}, 100^{\circ} \mathrm{C}, 1.01 \times 10^{5} \mathrm{~Pa}$ & 71 & $28 \min$ & [15] \\
\hline 3 & DBU, r.t. & - & - & [32] \\
\hline 4 & SDS (20 mol\%), water, $60^{\circ} \mathrm{C}$ & 98 & 3 & [22] \\
\hline 5 & TBAB, water & 91 & $25 \min$ & [23] \\
\hline 6 & TBAB, solvent-free & 91 & $21 \mathrm{~min}$ & [23] \\
\hline 7 & $\mathrm{TiO}_{2} / \mathrm{SO}_{4}^{-2}, \mathrm{H}_{2} \mathrm{O}, 80^{\circ} \mathrm{C}$ & 88 & 30 & [30] \\
\hline 8 & $\mathrm{SiO}_{2} \mathrm{Cl}, \mathrm{CH}_{2} \mathrm{Cl}_{2}, 40^{\circ} \mathrm{C}$ & 85 & 3.5 & [28] \\
\hline 9 & DBSA (25 mol\%), $\mathrm{H}_{2} \mathrm{O}$ :Ethanol, $80^{\circ} \mathrm{C}$ & 90 & $60 \min$ & this work \\
\hline 10 & DBSA (25 mol\%), $\mathrm{H}_{2} \mathrm{O}$ :Ethanol, MV & 90 & $4.5 \mathrm{~min}$ & this work \\
\hline
\end{tabular}




\section{Experimental}

\subsection{Instruments and Characterization}

IR spectra were recorded on a Perkin-Elmer FT-IR 240-C spectrophotometer (KBr). ${ }^{1} \mathrm{H}-\mathrm{NMR}$ and ${ }^{13} \mathrm{C}-\mathrm{NMR}$ spectra were run on Bruker spectrometers at $400 \mathrm{MHz}$ for ${ }^{1} \mathrm{H}-\mathrm{NMR}$ and $100 \mathrm{MHz}$ for ${ }^{13} \mathrm{C}$-NMR. The melting points were determined using an Electrotermal 9100 apparatus. The reactions were monitored by thin layer chromatography and the products were identified either fully or in the comparison of melting points and spectroscopic data with the previously reported ones.

\subsection{General Procedure for the Synthesis of 3,3-Arylidene Bis(4-Hydroxy-2Hchromen-2-Ones) Derivatives (Method A)}

A mixture of 4-hydroxycoumarin ( $2 \mathrm{mmol}, 0.324 \mathrm{~g}$ ), substituted benzaldehydes (1 mmol, $0.106 \mathrm{~g}$ ), and DBSA $(0.25 \mathrm{mmol}, 0.326 \mathrm{~g})$ was stirred at reflux in $5 \mathrm{ml}$ ethanol-water mixture (1:1). The progress of the reaction was monitored by TLC. After the reaction completion and upon its cooling, the solid material was precipitated from the solution. The precipitates were filtered off, washed with water, and were recrystalized from EtOH to obtain pure 3,3-arylidene bis(4-hydroxy-2Hchromen-2-ones) derivatives as yellow-white solids (60\% - 90\% yields).

\subsection{General Procedure (Method B)}

A mixture of 4-hydroxycoumarin ( $2 \mathrm{mmol}, 0.324 \mathrm{~g}$ ), substituted benzaldehydes (1 mmol, $0.106 \mathrm{~g}$ ), and DBSA $(0.25 \mathrm{mmol}, 0.326 \mathrm{~g})$ in $5 \mathrm{ml}$ ethanol-water mixture (1:1) was inserted in a microwave oven (Samsung, Model KE300R) at $450 \mathrm{~W}$ for an appropriate period of time (Table 1, Method B). The reaction was followed by TLC. After the reaction completion, its mass was cooled down to $25^{\circ} \mathrm{C}$. The solid residue were filtered off, washed with water, and were recrystalized from EtOH (68\% - 93\% yields).

\subsection{The Spectral Data of Unreported Compound 3q}

4-hydroxy-3-(((4-hydroxy-2-oxo-2H-chromen-3-yl)(2-(prop-2-ynyloxy)naphthalen-3-yl)methyl)-2H-chromen-2one (3q): $\mathrm{Mp}=168^{\circ} \mathrm{C}-172^{\circ} \mathrm{C}$. IR $\left(\mathrm{KBr}, \mathrm{cm}^{-1}\right): 3450,3271,3074,2148,1661 .{ }^{1} \mathrm{H}$ NMR $\left(400 \mathrm{MHz}, \mathrm{CDCl}_{3}\right): \delta=$ 1.58 (s, $1 \mathrm{H}, \mathrm{CH}), 2.34$ (t, $1 \mathrm{H}, J=2.4 \mathrm{~Hz}, \equiv \mathrm{CH}), 4.56$ (dd, $\left.J=9.6,2.4 \mathrm{~Hz}, \mathrm{CH}_{2}-\mathrm{O}\right), 6.44$ (m, 2H, H-arom), 7.37 7.43 (m, 6H, H-arom), 7.64 - 7.69 (m, 4H, H-arom), 8.06 (s, 2H, H-arom), 10.90 (s, 1H, OH), 11.75 (s, 1H, OH). ${ }^{13} \mathrm{C}$ NMR $\left(100 \mathrm{MHz}, \mathrm{CDCl}_{3}\right) \delta$ : 34.3, 56.9, 116.6, 116.7, 118.0, 118.1, 119.2, 124.3, 124.4, 124.5, 124.7, 124.8, 124.9, 130.9, 132.6, 132.9, 130.1, 132.6, 132.9, 133.1, 133.8, 135.2, 152.1, 152.2.

\section{References}

[1] Murray, R.D.H., Mendez, J. and Brown, S.A. (1982) The Natural Coumarins. Wiley, Chichester.

[2] Cravotto, G., Nano, G.M., Palmisano, G. and Tagliapietra, S. (2003) The Reactivity of 4-Hhydroxycoumarin under Heterogeneous High-Intensity Sonochemical Conditions. Synthesis, 8, 1286-1292.

[3] Jurd, L., Corse, J., King, A.D., Bayne, H. and Mihara, K. (1971) Antimicrobial Properties of Umbelliferone Derivatives. Phytochemistry, 10, 2965-2970. http://dx.doi.org/10.1016/S0031-9422(00)97333-3

[4] Ojala, T., Remes, S., Haansuu, P., Vuorela, H., Hiltunen, R., Haahtela, K. and Vuorela, P. (2000) Antimicrobial Activity of Some Coumarin Containing Herbal Plants Growing in Finland. Journal of Ethnopharmacology, 73, $299-305$. http://dx.doi.org/10.1016/S0378-8741(00)00279-8

[5] Laurin, P., Klich, M., Dupis-Hamelin, C., Mauvais, P., Lassaigne, P., Bonnefoy, A. and Musicki, B. (1999) Synthesis and in Vitro Evaluation of Novel Highly Potent Coumarin Inhibitors of Gyrase B. Bioorganic Medical Chemistry Letter, 9, 2079-2084. http://dx.doi.org/10.1016/S0960-894X(99)00329-7

[6] Donnelly, A.C., Mays, J.R., Burlison, J.A., Nelson, J.T., Vielhauer, G., Holzbeierlein, J. and Blagg, B.S.J. (2008) Synthesis, and Evaluation of Coumarin Ring Derivatives of the Novobiocin Scaffold That Exhibit Antiproliferative Activity. Journal of Organic Chemistry, 73, 8901-8920. http://dx.doi.org/10.1021/jo801312r

[7] Periers, A.-M., Laurin, P., Ferroud, D., Haesslein, J.-L., Klich, M., Dupuis-Hamelin, C., Mauvais, P., Lassaigne, P., Bonnefoy, A. and Musicki, B. (2000) Coumarin Inhibitors of Gyrase B with $N$-Propargyloxy-Crbamate as an Effective Pyrrole Bioisostere. Bioorganic Medical Chemistry Letter, 10, 161-165. http://dx.doi.org/10.1016/S0960-894X(99)00654-X

[8] Musicki, B., Periers, A.M., Laurin, P., Ferroud, D., Benedetti, Y., Lachaud, S., Chatreaux, F., Haesslein, J.L., IItis, A. 
and Pierre, C. (2000) Improved Antibacterial Activities of Coumarin Antibiotics Bearing 5',5'-Dialkylnoviose: Biological Activity of RU79115. Bioorganic Medical Chemistry Letter, 10, 1695-1699.

http://dx.doi.org/10.1016/S0960-894X(00)00304-8

[9] Zaneva, O., Manolov, I. and Danchev, N. (2005) Toxicological and Pharmacological Investigations of Newly Synthesized Derivatives of 4-Hydroxycoumarin. Pharmacia (Sofia), 1-2, 85-89.

[10] Craciun, A.M., Groenen-van Dooren, M.M.C.L., Thijssen, H.H. and Vermeer, C. (1998) Induction of Prothrombin Synthesis by K-Vitamins Compared in Vitamin K-Dependent and in Brodifacoum-Treated Rats. Biochimica et Biophysica Acta, 1380, 75-81. http://dx.doi.org/10.1016/S0304-4165(97)00134-7

[11] Moran, S. (2001) The Efficacy of the Flocoumafen Wax Block Bait to Control the Field Rodents Microtus guentheri and Meriones tristrami. Crop Protectio, 20, 529-533. http://dx.doi.org/10.1016/S0261-2194(01)00016-3

[12] Završnik, D., Muratović, S., Makuc, D., Plavec, J., Cetina, M., Nagl, A., Clercq, E.D., Balzarini, J. and Mintas, M. (2011) Benzylidene-Bis-(4-Hydroxycoumarin) and Benzopyrano-Coumarin Derivatives: Synthesis, ${ }^{1} \mathrm{H} /{ }^{13} \mathrm{C}-\mathrm{NMR}$ Conformation and X-Ray Crystal Structure Studies and in Vitro Antiviral Activity Evaluations. Molecules, 16, 6023-6040. http://dx.doi.org/10.3390/molecules16076023

[13] Ilia, M., Caecilia, M.M. and Nicolay, D. (2006) Synthesis, Structure, Toxicological and Pharmacological Investigations of 4-Hydroxycoumarin Derivatives. European Journal of Medical Chemistry, 41, 882-890. http://dx.doi.org/10.1016/j.ejmech.2006.03.007

[14] Manolov, I.I. (1998) Aldehyde Condensation Products of 4-Hydroxycoumarin and Schiff Bases. Tetrahedron Letters, 39, 3041-3042. http://dx.doi.org/10.1016/S0040-4039(98)00351-7

[15] Kidwai, M., Bansal, V., Mothsra, P., Saxena, S., Somvanshi, R.K., Dey, S. and Singh, T.P. (2007) Molecular Iodine: A Versatile Catalyst for the Synthesis of Bis(4-Hydroxycoumarin) Methanes in Water. Journal of Molecular Catalysis A: Chemical, 268, 76-81. http://dx.doi.org/10.1016/j.molcata.2006.11.054

[16] Sanghetti, J.N., Kokare, N.D. and Shinde, D.B. (2009) Water Mediated Efficient One-Pot Synthesis of Bis-(4-hydroxycoumarin)methanes. Green Chemistry Letters and Reviews, 2, 233-235. http://dx.doi.org/10.1080/17518250903393874

[17] Hagiwara, H., Fujimoto, N., Suzuki, T. and Ando, M. (2000) Synthesis of Methylenebis(4-Hydroxy-2-Pyrone) or Methylenebis(4-Hydroxycoumarin) Derivatives by Organic Solid State Reaction. Heterocycles, 53, 549-552. http://dx.doi.org/10.3987/COM-99-8817

[18] Elgamal, M.H.A., Shalaby, N.M.M., Shaban, M.A., Duddeck, H., Mikhova, B., Simon, A. and Toth, G. (1997) Synthesis and Spectroscopic Investigation of Some Dimeric Coumarin and Furanocoumarin Models. Monatshefte für Chemie/ Chemical Monthly, 128, 701-712.

[19] Hagiwara, H., Miya, S., Suzuki, T., Ando, M., Yamamoto, I. and Kato, M. (1999) Tandem Nucleophilic Reaction Leading to Hydrofurans: Application to One-Pot Synthesis of Antitumor Naphthofuran Natural Product. Heterocycles, 51, 497-500. http://dx.doi.org/10.3987/COM-98-8430

[20] Sheikhhosseini, E. (2012) Synthesis of 3,3-Arylidene bis(4-hydroxycoumarin) Catalyzed by $\mathrm{LiClO}_{4}$. Trend in Modern Chemistry, 3, 34-37.

[21] Li, W., Wang, Y., Wang, Z., Dai, L. and Wang, Y. (2011) Novel $\mathrm{SO}_{3} \mathrm{H}-$ Functionalized Ionic Liquids Based on Benzimidazolium Cation: Efficient and Recyclable Catalysts for One-Pot Synthesis of Biscoumarin Derivatives. Catalysis Letters, 141, 1651-1658. http://dx.doi.org/10.1007/s10562-011-0689-9

[22] Mehrabi, H. and Abusaidi, H. (2010) Synthesis of Biscoumarin and 3,4-Dihydropyrano[c]chromene Derivatives Catalysed by Sodium Dodecyl Sulfate (SDS) in Neat Water. Journal of Iranian Chemical Society, 7, 890-894.

[23] Khurana, J.M. and Kumar, S. (2009) Tetrabutylammonium Bromide (TBAB): A Neutral and Efficient Catalyst for the Synthesis of Biscoumarin and 3,4-Dihydropyrano[c]chromene Derivatives in Water and Solvent-Free Conditions. Tetrahedron Letters, 50, 4125-4127. http://dx.doi.org/10.1016/j.tetlet.2009.04.125

[24] Siddiqui, Z. and Farooq, F. (2011) Zn(Proline) ${ }_{2}$ : A Novel Catalyst for the Synthesis of Dicoumarols. Catalysis Science \& Technology, 1, 810-816.

[25] Khurana, J.M. and Kumar, S. (2010) Ionic Liquid: An Efficient and Recyclable Medium for the Synthesis of Octahydroquinazolinone and Biscoumarin Derivatives. Monatshefte für Chemie/Chemical Monthly, 141, 561-564.

[26] Zhou, J.F., Gong, G.X., An, L.T., Sun, X.J. and Zhu, F.X. (2009) Synthesis of 3,3-Arylidene Bis(4-Hydroxycoumarin) Catalyzed by Sulfamic Acid in Aqueous Media under Microwave Irradiation. Chinese Journal of Organic Chemistry, 29, 1988-1991.

[27] Tabatabaeian, K., Heidari, H., Khorshidi, A., Mamaghani, M. and Mahmoodi, N. (2012) Synthesis of Biscoumarin Derivatives by the Reaction of Aldehydes and 4-Hydroxycoumarin Using Ruthenium(III) Chloride Hydrate as a Versatile Homogeneous Catalyst. Journal of the Serbian Chemical Society, 77, 407-413. http://dx.doi.org/10.2298/JSC110427189T 
[28] Karimian, R., Piri, F., Safari, A.A. and Davarpanah, S.J. (2013) One-Pot and Chemoselective Synthesis of Bis(4-Hydroxycoumarin) Derivatives Catalyzed by Nano Silica Chloride. Journal of Nanostructure in Chemistry, 3, 52.

[29] Sadeghi, B. and Ziya, T. (2013) A Fast, Highly Efficient, and Green Protocol for Synthesis of Biscoumarins Catalyzed by Silica Sulfuric Acid Nanoparticles as a Reusable Catalyst. Journal of Chemistry, 2013, Article ID: 179013.

[30] Karmakar, B., Nayak, A. and Banerji, J. (2012) Sulfated Titania Catalyzed Water Mediated Efficient Synthesis of Dicoumarols-A Green Approach. Tetrahedron Letters, 53, 4343-4346.

[31] Hamdi, N., Purta, M.C. and Valerga, P. (2008) Synthesis, Structure, Antimicrobial and Antioxidant Investigations of Dicoumarol and Related Compounds. European Journal of Medicinal Chemistry, 43, 2541-2548. http://dx.doi.org/10.1016/j.ejmech.2008.03.038

[32] Shaterian, H.R. and Honarmand, M. (2009) Uncatalyzed, One-Pot Synthesis of 3,3'-(Benzylene)Bis(4-Hydroxy-2HChromen-2-One) Derivatives under Thermal Solvent-Free Conditions. Chinese Journal of Chemistry, 27, 1795-1800. http://dx.doi.org/10.1002/cjoc.200990302

[33] Al-Kadasi, A.M.A. and Nazeruddin, G.M. (2012) Ultrasound Assisted Catalyst-Free One-Pot Synthesis of Biscoumarins in Neat Water. International Journal of Chemical Sciences, 10, 324-330.

[34] Mao, P.C.M., Mouscadet, J.F., Leh, H., Auclair, C. and Hsu, L.Y. (2002) Chemical Modification of Coumarin Dimer and HIV-1 Integrase Inhibitory Activity. Chemical \& Pharmaceutical Bulletin, 50, 1634-1637. http://dx.doi.org/10.1248/cpb.50.1634

[35] Su, C.X., Mouscadet, F., Chiang, C.C., Tsai, H.J. and Hsu, L.Y. (2006) HIV-1 Integrase Inhibition of Biscoumarin Analogues. Chemical \& Pharmaceutical Bulletin, 54, 682-686. http://dx.doi.org/10.1248/cpb.54.682

[36] Manabe, K., Mori, Y. and Kobayashi, S. (2001) Three-Component Carbon-Carbon Bond-Forming Reactions Catalyzed by a Brønsted Acid-Surfactant-Combined Catalyst in Water. Tetrahedron, 57, 2537-2544. http://dx.doi.org/10.1016/S0040-4020(01)00081-3

[37] Peng, Y.Y., Zhang, Q.L., Yuan, J.J. and Cheng, J.P. (2008) A Facile Aqueous Synthesis of Bis(Indol-3-yl)Alkanes Catalyzed by Dodecylbenzenesulfonic Acid. Chinese Journal of Chemistry, 26, 2228-2232. http://dx.doi.org/10.1002/cjoc.200890396

[38] Shiri, M. and Zolfigol, M.A. (2009) Surfactant-Type Catalysts in Organic Reactions. Tetrahedron, 65, 587-598. http://dx.doi.org/10.1016/j.tet.2008.09.085

[39] Han, Y. and Chu, Y. (2005) The Catalytic Properties and Mechanism of Cyclohexane/DBSA/Water Microemulsion System for Esterification. Journal of Molecular Catalysis A: Chemical, 237, 232-237. http://dx.doi.org/10.1016/j.molcata.2005.04.058

[40] Sheikhhosseini, E., Ghazanfari, D. and Nezamabadi, V. (2013) A New Method for Synthesis of Tetrahydrobenzo[b]-Pyrans and Dihydropyrano[c]Chromenes Using $p$-Dodecylbenzenesulfonic Acid as Catalyst in Water. Iranian Journal of Catalysis, 3, 197-201.

[41] Hashemi, H. and Sardarian, A.R. (2013) 4-Dodecylbenzenesulfonic Acid (DBSA) as an Efficient and Recyclable Catalyst for Synthesis of 14-Aryl- and 14-Alkyl-14-H-Dibenzo[a,j]Xanthenes under Solvent-Free Conditions. Iranian Journal of Science \& Technology, A1, 75-82.

[42] Bigdeli, M.A., Gholami, G. and Sheikhhosseini, E. (2011) P-Dodecylbenzenesulfonic Acid (DBSA), a Brønsted AcidSurfactant Catalyst for Biginelli Reaction in Water and under Solvent Free Conditions. Chinese Chemical Letters, 22, 903-906. http://dx.doi.org/10.1016/j.cclet.2010.12.030 